\title{
Bounding of near-fault ground motion based on radiated seismic energy with a consideration of fault frictional mechanisms*
}

\author{
Baoping Shi ${ }^{\star}$ Boyan Liu and Lingyuan Meng \\ Earth Science College of the Graduate School, Chinese Academy of Sciences, Beijing 100049, China
}

\begin{abstract}
The energy radiated as seismic waves strongly depends on the fault rupture process associated with rupture speed and dynamic frictional mechanisms involved in the fault slip motion. Following McGarr and Fletcher approach, we derived a physics-based relationship of the weighted average fault slip velocity vs apparent stress, rupture speed and static stress drop based on a dynamic circular fault model. The resultant function can be approximately used to bound near-fault ground motion and seismic energy associated with near-fault coseismic deformation. Fault frictional overshoot and undershoot mechanisms governed by a simple slip-weakening constitutive relation are included in our consideration by using dynamic rupture models named as M- and D-models and proposed by Madariaga (1976) and Boatwright. We applied the above function to the 2008 great Wenchuan earthquake and the $1999 \mathrm{Jiji}$ (Chi-Chi) earthquake to infer the near-fault ground motion called slip weighted average particle velocity and obtained that such model-dependent prediction of weighted average ground velocities is consistent to the results derived from the near-fault strong motion observations. Moreover, we compared our results with the results by McGarr and Fletcher approach, and we found that the values of the weighted average particle velocities we obtained for these two earthquakes are generally smaller and closer to the values by direct integration of strong motion recordings of the near-fault particle velocity waveform data. In other words, if this result comes to be true, it would be a straightforward way used to constrain the near-fault ground motion or to estimate source parameters such as rupture speed, static and dynamic stress drops.
\end{abstract}

Key words: stress drop; radiated energy; apparent stress; circular-fault-model; rupture speed CLC number: P315.9 Document code: A

\section{Introduction}

As we know, the radiated seismic energy $E_{\mathrm{s}}$ and the seismic moment $M_{\mathrm{o}}$ are two of the most fundamental earthquake source parameters used to infer fault rupture properties. In practice, the seismic moment is commonly used to measure the size of earthquake and obtained from asymptotically low frequencies of ground displacement. $E_{\mathrm{s}}$ represents the high frequency spectral information about the corner frequency. From a practical point of view, $E_{\mathrm{s}}$ and energy magnitude $M_{\mathrm{e}}$ are good measures of the potential of earthquakes to produce damage ground motion. The ratio of these two parameters multiplied by $\mu$, the modulus of fault rigidity, yields the apparent stress $\tau_{\mathrm{a}}$ (Wyss and Brune, 1968):

\footnotetext{
* Received 5 May 2009; accepted in revised form 21 May 2009; published 10 August 2010.

* Corresponding author. e-mail: bshi@gucas.ac.cn

(C) The Seismological Society of China and Springer-Verlag Berlin Heidelberg 2010
}

$\tau_{\mathrm{a}}=\mu E_{\mathrm{s}} / M_{\mathrm{o}}, \tau_{\mathrm{a}}$ is the stress that causes seismic energy radiation and corresponds to radiated seismic energy $E_{\mathrm{s}}$ per unit area per unit slip.

Choy et al (2006) found systematic variations in apparent stress as a function of focal mechanism and the distribution of apparent stresses is strongly related to tectonic circumstances. Moreover, Choy and Boatwright (2009) also indicated that the differential energy radiation from two earthquakes (Kyushu and Tottori) in Japan with identical moment magnitude. The apparent stress for Kyushu earthquake is $1 / 4$ smaller than the apparent stress for the Tottori earthquake. As pointed out by Choy and Boatwright (2009), this result has implications for the seismic engineering community because it suggests that seismic moment alone is insufficient to quantify seismic hazard potential. In other aspects, Brune and Thatcher (2002) argued that, for the 1999 Jiji (Chi-Chi) $M_{\mathrm{W}} 7.6$ thrusting earthquake, the apparent stress derived from near-fault strong motion data is much larger than 
that obtained from teleseismic data, and this inconsistence could be explained by fault geometry effect in which the ground motions on the footwall were much less than those on the hanging wall, resulting in much less energy radiating downward compared with the energy trapped in the hanging wall (Brune and Thatcher, 2002).

McGarr and Fletcher (2001) introduced a technique for estimating apparent stress and radiated seismic energy. They found that the ratio of far-field to near-fault energies is typically less than $1 / 3$, concluding that most of the energy remains near the fault and is associated with permanent fault deformation. With a combination of the portion of the strain energy change that is not dissipated in the frictional process and a dynamic circular fault model derived by Madariaga (1976) which is called M-model later on in this paper, McGarr and Fletcher derived the ratio of far-field $E_{\mathrm{s}}$ to near-fault energy $E_{\text {nf }}$ :

$$
\frac{E_{\mathrm{s}}}{E_{\mathrm{nf}}}=\frac{\tau_{\mathrm{a}}}{\tau_{\mathrm{a}}+\Delta \tau_{\mathrm{s}} / 2},
$$

where $\Delta \tau_{\mathrm{s}}$ is the static stress drop. In fact, the above equation also implies that the near-fault apparent stress could be expressed by $\tau_{\mathrm{a}}^{n}=\tau_{\mathrm{a}}+0.5 \Delta \tau_{\mathrm{s}}$, and for the M-model (Boatwright, 1980), the ratio of static to dynamic stress drops has:

$$
\frac{\Delta \tau_{\mathrm{s}}}{\Delta \tau_{\mathrm{d}}}=\rho_{\mathrm{o}} \frac{7 \pi}{24} \frac{C\left(\frac{v_{\mathrm{R}}}{\beta}\right)}{\frac{v_{\mathrm{R}}}{\beta}}>1
$$

where $\Delta \tau_{\mathrm{d}}$ is the dynamic stress drop [or effective stress drop, (Brune, 1970)]. $\beta$ and $v_{\mathrm{R}}$ are the shear-wave and rupture speeds, respectively. $C\left(v_{\mathrm{R}} / \beta\right)$ is the Kostrov function (Dahlen, 1974), with values of 0.59 at $v_{\mathrm{R}} / \beta=$ $0.6,0.71$ at $v_{\mathrm{R}} / \beta=0.75$, and 0.82 at $v_{\mathrm{R}} / \beta=0.9$, respectively. The scale factor $\rho_{\mathrm{o}}=1.52$ and 1.0 correspond to the M- and D-models, respectively (Madariaga, 1976, Boatwright, 1980). In fact, the inequality of $\Delta \tau_{\mathrm{s}} / \Delta \tau_{\mathrm{d}}>1$ also implies that a dynamic frictional overshoot (Savage and Wood, 1971) occurs during an earthquake fault motion. In general, Ramon-Zuniga (1993) proposed a parameter, denoted by $\varepsilon=\Delta \tau_{\mathrm{s}} /\left(\tau_{\mathrm{a}}+0.5 \Delta \tau_{\mathrm{s}}\right)$, to classify the frictional models: $\varepsilon$ is greater than 1 for a frictional overshoot mechanism and $\varepsilon$ is less 1 for a frictional undershoot mechanism (Kanamori, 2006) or a partial stress drop model (Brune, 1970). Therefore, the result of
$\varepsilon=\Delta \tau_{\mathrm{s}} /\left(\tau_{\mathrm{a}}^{\mathrm{n}}+0.5 \Delta \tau_{\mathrm{s}}\right)<1$ based on the McGarr and Fletcher's approach given by equation (1) always indicates a dynamic frictional undershoot if we take equation (1) (near-fault effect) into this consideration. Obviously, the frictional mechanism inferred from the near-fault solution is inconsistent with far-field solution given by equation (1) which was derived from the M-model. On the other hand, the maximum overshoot occurs when $\varepsilon=2$ in which $\tau_{\mathrm{a}}=0$ and $\Delta \tau_{\mathrm{s}} / \Delta \tau_{\mathrm{d}}=2$ if the fracture energy is assumed to be zero. Recent study from dynamic modeling based on the slip-weakening model gave that the fracture energy, radiated seismic energy and relaxing work done due to the dynamic frictional overshoot are $60 \%, 23 \%$ and $17 \%$ of the energy associated with the static stress drop (Favreau and Archuleta, 2003), respectively. Such relaxing work also implies that the portion of the strain energy change on the fault could be further partitioned into two parts: one is directly associated with near-fault co-seismic deformation accompanied by high frequency radiation, and the other is the work done by the stress relaxation on the fault after the arrest of the slip as discussed by Favreau and Archeluta (2003).

In this study, following the approach introduced by McGarr and Fletcher (2001, 2002), we will re-derive the mathematical expression relating to the seismic energy in the near-fault based on the slip-weakening model for a circular fault model. We will also show that the derived new function or a modification of McGarr and Fletcher's equation have a uniform expression in which the frictional overshoot, undershoot and total stress drop model are involved in the consideration without any further assumption. With a combination of far-field radiated energy $E_{\mathrm{s}}$ and seismic moment obtained from teleseismic inversion, we propose a useful way used to bound near-fault particle motions defined by slip-weighted average slip rate. Finally, two sets of real strong motion data of velocity waveforms from the $1999 M_{\mathrm{W}} 7.6 \mathrm{Jiji}$ earthquake and the $2008 M_{\mathrm{W}} 7.9$ Wenchuan earthquake are used to infer the near-fault ground motion associated with the rupture properties.

\section{Brief model}

\subsection{Energy partition}

In general, the energy radiated through a surface $S_{0}$ completely enclosing a finite fault can be expressed as (Rivera and Kanamori, 2005): 


$$
\begin{gathered}
E_{\mathrm{s}}=\frac{1}{2} \int_{\Sigma_{\mathrm{o}}}\left(\sigma_{i j}^{0}+\sigma_{i j}^{1}\right) n_{j} \Delta u_{i}^{1} \mathrm{~d} S-\int_{\Sigma_{\mathrm{o}}} 2 \gamma_{\text {eff }} \mathrm{d} S- \\
\int_{t_{0}}^{t_{1}} \mathrm{~d} t \int_{\Sigma(t)} \sigma_{i j} n_{j} \Delta \dot{u}_{i} \mathrm{~d} S+\frac{1}{2} \int_{S_{\mathrm{o}}}\left(\sigma_{i j}^{0}-\sigma_{i j}^{1}\right) n_{j} u_{i}^{1} \mathrm{~d} S,
\end{gathered}
$$

where $\mathrm{d} S$ is the surface element, $\Sigma_{\mathrm{o}}$ is an open surface representing the fault plane, and $\sigma_{i j}, \Delta u_{i}, n_{j}, t_{0}$ and $t_{1}$ are the stress, dislocation on $\Sigma$, a unit normal to $\Sigma$, the time when slip begins at point $x$ on $\Sigma$, and an arbitrary time after slip motion has ceased, respectively, and $\Sigma(t)$ is the ruptured fault surface at time $t$, and $\gamma_{\text {eff }}$ is the effective fracture energy. The superscripts 1 and 2 refer to before and after the slip occurred. The first term in equation (3) is the elastic energy on the fault, which does not depend on the instantaneous stress $\sigma_{i j}$, but only on the initial and final stress values; the last term vanishes if $S_{0}$ is taken far enough from the fault, because $u_{i}^{1}$ and $\left(\sigma_{i j}^{0}-\sigma_{i j}^{1}\right)$ decrease as $1 / r^{2}$ and $1 / r^{3}$, respectively. The final expression for $E_{\mathrm{s}}$ in the far-field is given by

$$
\begin{gathered}
E_{\mathrm{s}}=\frac{1}{2} \int_{\Sigma_{\mathrm{o}}}\left(\sigma_{i j}^{0}-\sigma_{i j}^{1}\right) n_{j} \Delta u_{i}^{1} \mathrm{~d} S-\int_{\Sigma_{\mathrm{o}}} 2 \gamma_{\text {eff }} \mathrm{d} S- \\
\int_{t_{0}}^{t_{1}} \mathrm{~d} t \int_{\Sigma(t)} \sigma_{i j} n_{j} \Delta \dot{u}_{i} \mathrm{~d} S,
\end{gathered}
$$

An alternative expression of equation (4) can be obtained after integrating last term by parts:

$$
\begin{gathered}
E_{\mathrm{s}}=\frac{1}{2} \int_{\Sigma_{\mathrm{o}}}\left(\sigma_{i j}^{0}-\sigma_{i j}^{1}\right) n_{j} \Delta u_{i}^{1} \mathrm{~d} S-\int_{\Sigma_{\mathrm{o}}} 2 \gamma_{\text {eff }} \mathrm{d} S+ \\
\int_{t_{0}}^{t_{1}} \mathrm{~d} t \int_{\Sigma(t)} \dot{\sigma}_{i j} n_{j} \Delta u_{i} \mathrm{~d} S .
\end{gathered}
$$

In equation (5), the first term corresponds to the strain energy change before and after the earthquake faulting, the second and third terms give the energy absorbed on the fault plane, which contains the instantaneous shear traction $\tau_{i}=\sigma_{i j} n_{j}$. The initial and final shear tractions are $\tau_{i}^{k}=\sigma_{i j}^{k} n_{j}(k=0,1)$. Rivera and Kanamori (2005) pointed out that the term $\gamma_{\text {eff }}$ in the above equations contained all the stress and velocity singularities related to rupture propagation, and the integral over $\Sigma(t)$ had no singularities. Therefore, we can exchange the order of integration, and the last term in equation (5) gives that

$$
\begin{gathered}
\int_{t_{0}}^{t_{1}} \mathrm{~d} t \int_{\Sigma(t)} \dot{\sigma}_{i j} n_{j} \Delta u_{i} \mathrm{~d} S=\int_{\Sigma(t)} \mathrm{d} S \int_{0}^{t_{m}} \dot{\sigma}_{i j} n_{j} \Delta u_{i} \mathrm{~d} t= \\
\tau_{i} \Delta u_{i}^{1}-\int_{0}^{t_{m}} \Delta u_{i} \mathrm{~d} t=-\int_{0}^{\Delta u_{i}^{1}}\left(\tau_{i}-\tau_{i}^{1}\right) \mathrm{d} \Delta u_{i} .
\end{gathered}
$$

The equation (5) can be written as

$$
\begin{gathered}
E_{\mathrm{s}}=\frac{1}{2} \int_{\Sigma_{\mathrm{o}}}\left(\tau_{i}^{0}-\tau_{i}^{1}\right) \Delta u_{i}^{1} \mathrm{~d} S-\int_{\Sigma_{\mathrm{o}}} 2 \gamma_{\text {eff }} \mathrm{d} S+ \\
\int_{\Sigma_{\mathrm{o}}} \int_{0}^{\Delta u_{i}^{1}}\left(\tau_{\mathrm{i}}-\tau_{i}^{1}\right) \mathrm{d} \Delta u_{i} \mathrm{~d} S .
\end{gathered}
$$

From equation (6), Cocco et al (2006) indicated that if the final stress $\tau_{i}^{1}$ is equal to the residual stress $\tau_{\mathrm{f}}$ and the dynamic stress $\tau_{\mathrm{d}}$ is constant and equal to the minimum stress, the last term (Kostrov term) corresponds to the fracture energy. In general case, the final stress does not correspond to the dynamic stress value, the fault rupture processes undertake the frictional undershoot in which $\tau_{i}^{1}>\tau_{f}$ or frictional overshoot in which $\tau_{i}^{1}<\tau_{f}$. Savage and Wood (1971) exploited the above relation in the form of $\tau_{\mathrm{a}}=\mu E_{\mathrm{s}} / M_{\mathrm{o}}<\Delta \tau_{\mathrm{s}} / 2$ ( $\Delta \tau_{\mathrm{s}}=\tau_{0}-\tau_{1}$ is the static stress drop, $\tau_{\mathrm{f}}$ the frictional stress, $\mu$ the shear rigidity, and $M_{\mathrm{o}}$ the scalar seismic moment) which is known as Savage and Wood inequality implying a frictional overshoot mechanism. Figure 1 shows two types of dynamic frictional model with a simple slip weakening frictional motion of faulting in which the frictional stress varies as a function of slip

$$
\tau=\left\{\begin{array}{ll}
\tau^{\mathrm{y}}-\left(\tau^{\mathrm{y}}-\tau_{\mathrm{f}}\right) \Delta u, & \Delta u \leq D_{\mathrm{c}} \\
\tau_{\mathrm{f}} & \Delta u \geq D_{\mathrm{c}}
\end{array},\right.
$$

where $D_{\mathrm{c}}$ is the critical slip weakening distance, $\tau^{\mathrm{y}}$ is the yield stress related to the fault strength, and $\tau_{i}^{1}=\tau_{\mathrm{f}}$ corresponds to a total stress drop model. Moreover, for the slip weakening model shown in Figure 1, the fracture energy in equation (6) is included in the Kostrov term, so that the effective surface energy does not lie within the stress versus slip curve, and it should be neglected in any other fault zone model.

For a fault zone model with the slip motion obeying the slip-weakening criterion and the frictional overshoot and undershoot are involved during the dynamic rupture, the equation (6) can be further simplified as

$$
E_{\mathrm{s}}=\frac{1}{2} \iint_{\Sigma_{\mathrm{o}}}\left(\tau_{i}^{0}-\tau_{i}^{1}\right) \Delta u_{i}^{1} \mathrm{~d} S-\iint_{\Sigma_{\mathrm{o}}} \mathrm{d} S \int_{0}^{\Delta u_{i}} \tau_{i} \mathrm{~d} \Delta u_{i}
$$

otherwise,

$$
E_{\mathrm{s}}=\frac{1}{2} \iint_{\Sigma_{\mathrm{o}}}\left(\tau_{i}^{0}-\tau_{i}^{1}\right) \Delta u_{i}^{1} \mathrm{~d} S+\iint_{\Sigma_{\mathrm{o}}} \mathrm{d} S \int_{0}^{\Delta u_{i}}\left(\tau_{\mathrm{f}}-\tau_{i}^{1}\right) \mathrm{d} \Delta u_{i}-E_{\mathrm{f}} .
$$

If $\tau_{i}^{1}=\tau_{\mathrm{f}}=$ consant is assumed during fault rupturing. The last term in equation (9) corresponds to fracture energy dissipated during a crack extending. 

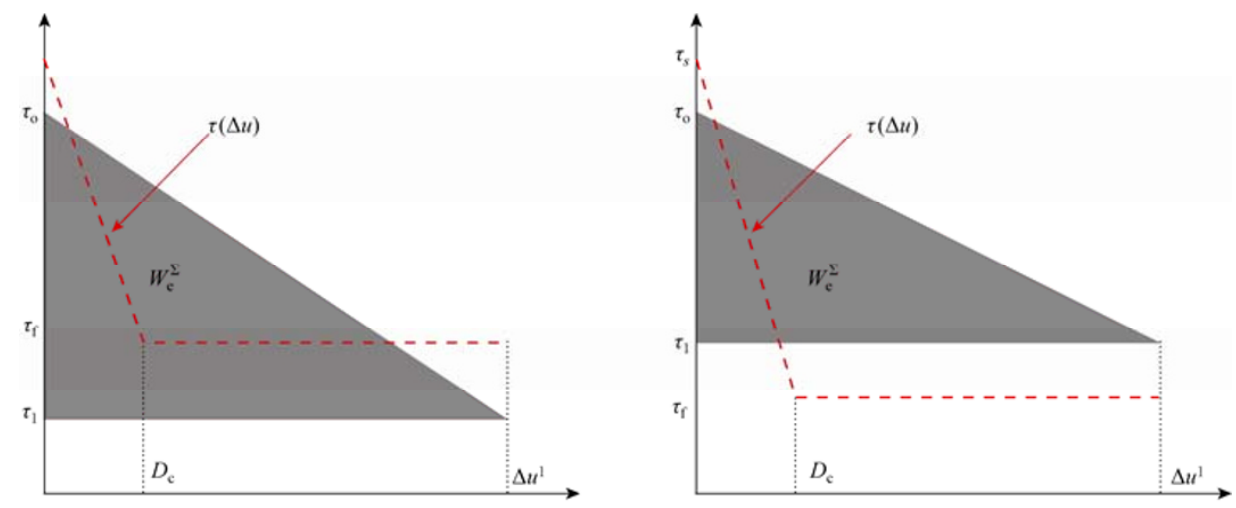

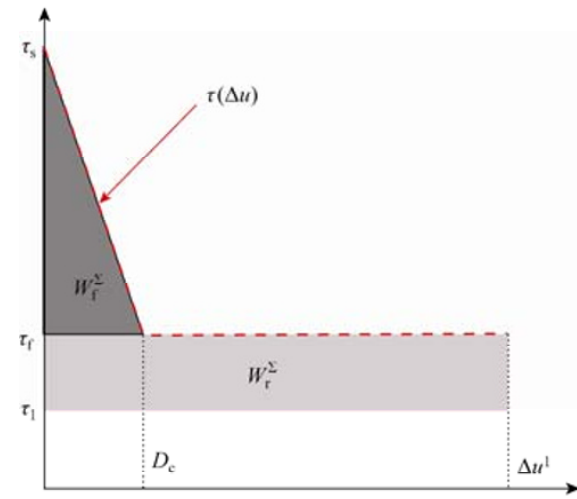

(a)

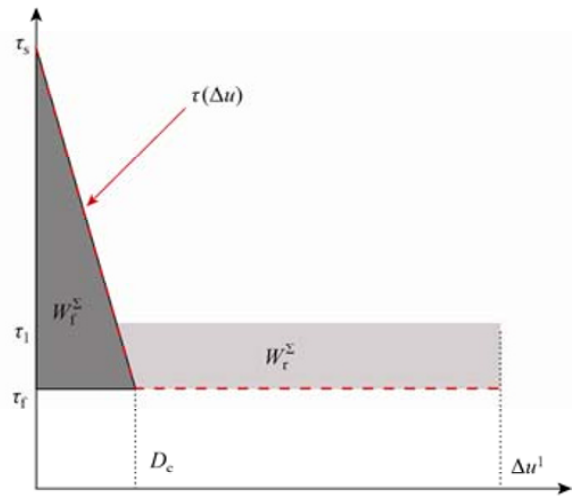

(b)

Figure 1 A simple frictional overshoot in the slip-weakening model (a), $w_{\mathrm{e}}^{\Sigma}$ is the elastostatic work provided by the elastic crust deformation, $w_{\mathrm{f}}^{\Sigma}$ is the fracture works pent at the rupture front and $w_{\mathrm{r}}^{\Sigma}$ is the relaxation work after the arrest of the slip. A simple frictional overshoot in the slip-weakening model (b), $w_{\mathrm{f}}^{\Sigma}$ is the fracture work spent at the rupture front, and $w_{\mathrm{r}}^{\Sigma}$ is the radiation friction work spent at the arrest (abrupt stress drop model). The radiated seismic energy density is given by $e_{q}=w_{\mathrm{e}}^{\Sigma}-w_{\mathrm{f}}^{\Sigma}-w_{\mathrm{r}}^{\Sigma}$ for a frictional overshoot and $e_{q}=w_{\mathrm{e}}^{\Sigma}-w_{\mathrm{f}}^{\Sigma}+w_{\mathrm{r}}^{\Sigma}$ for a frictional overshoot.

\subsection{Circular fault rupture model}

For a self-similar circular crack model with an given average slip displacement $S$, the energy dissipated as fracture work is $E_{\mathrm{f}}$ and $G=E_{\mathrm{f}}+\pi a^{2}\left(\tau_{\mathrm{f}}-\tau_{1}\right) S=0.5 \times$ $\pi a^{2}\left(\Delta \tau_{\mathrm{s}}-2 \tau_{\mathrm{a}}\right) S$ is the total energy dissipation in friction and fracture minus $\tau_{1} \pi a^{2} S$ if a frictional overshoot occurs. In general, for a circular fault model, the dynamic rupture behavior related to the slip displacement and slip velocity functions on the fault are shown in Figures 2a and $2 \mathrm{~b}$ (Boatwright, 1980) in which $a$ and $b$ corresponds to the M- and D-models, respectively. For a comparison purpose, Figure $2 \mathrm{c}$ also gives slip displacement and slip velocity functions resultant from the Brune model. Brune model is the ad hoc model which has been commonly used in the observation seismology to infer the earthquake source parameters such as fault size and static stress drop. In contrast, M- and D-model are the dynamic models which use an actual dynamic fracture simulation to associate the diameter (fault size) with the radiated signal and corner frequency. Both $\mathrm{M}$ - and D-models describe the source grows from a point on the fault with a uniform rupture velocity. For D-model, the rupture front begins to decelerate when the entire rupture heals, slowing continuously. In contrast, for M-model, the rupture has abrupt stopping at fixed rupture perimeter. The motion at an interior point continues in the rupture phase until the P-wave phase generated by the stopping of rupture front at the interior point at a certain time. From Figure 2, the average slip displacement and velocity for M-model is larger than those from D-model and Brune model. Actually, in the M- and D-models, the final slip distributions along the fault are 


$$
\left\{\begin{array}{l}
\Delta u_{i}^{1}=\frac{\rho_{\mathrm{o}} \Delta \dot{u}_{\mathrm{o}}}{v_{\mathrm{R}} a \sqrt{1-(r / a)^{2}}} \\
\Delta \dot{u}_{\mathrm{o}}=\frac{\Delta \tau_{\mathrm{d}}}{\mu C\left(\frac{v_{\mathrm{R}}}{\beta}\right) \beta} \approx \frac{v_{R} \Delta \tau_{\mathrm{d}}}{\mu}
\end{array}\right.
$$

where $\rho_{0}=1.52$ and 1.0 correspond to the $\mathrm{M}$ - and D-models, respectively. In equation (10), $\Delta \tau_{\mathrm{d}}$ is the dynamic stress drop (or the effective stress, Brune, 1970)
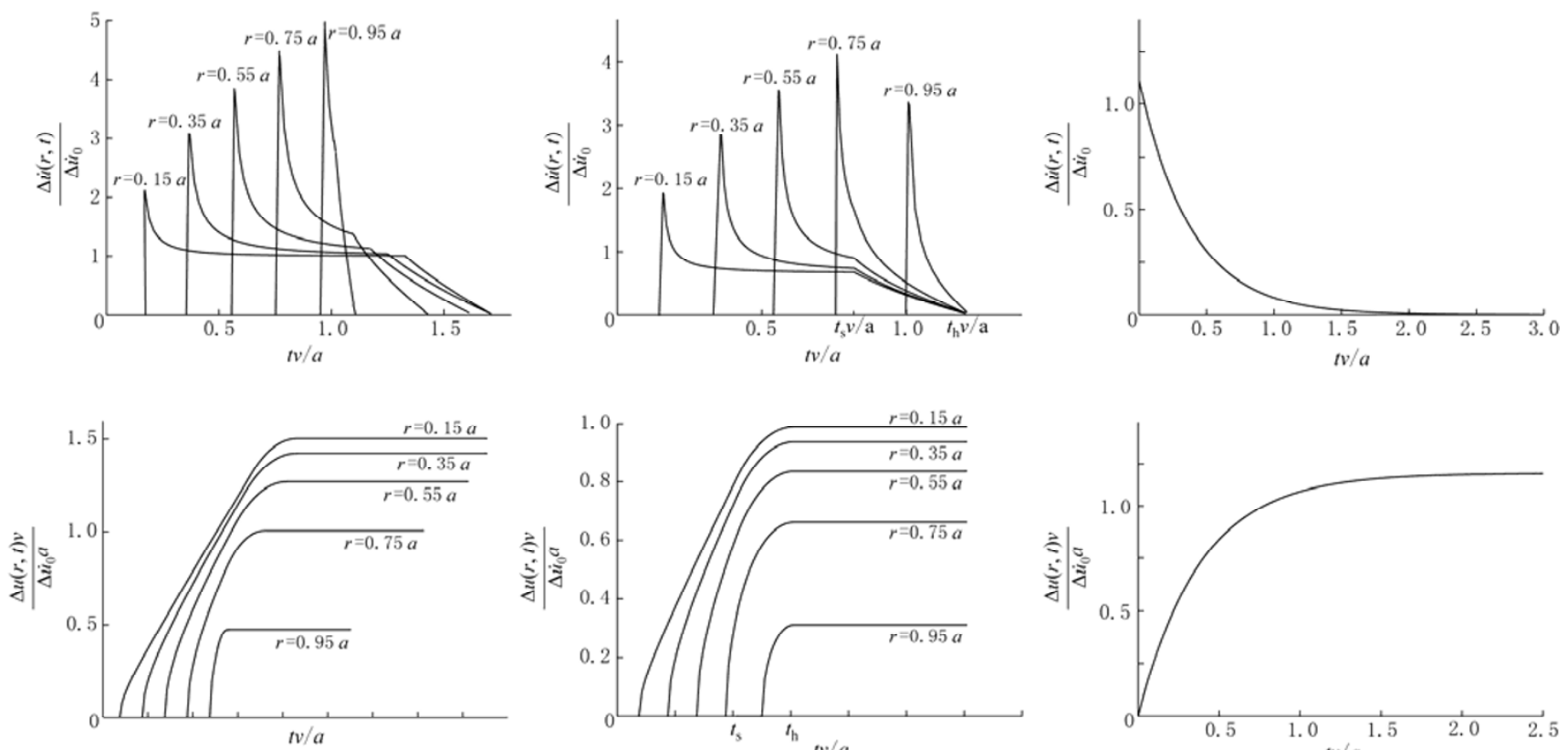

(a)

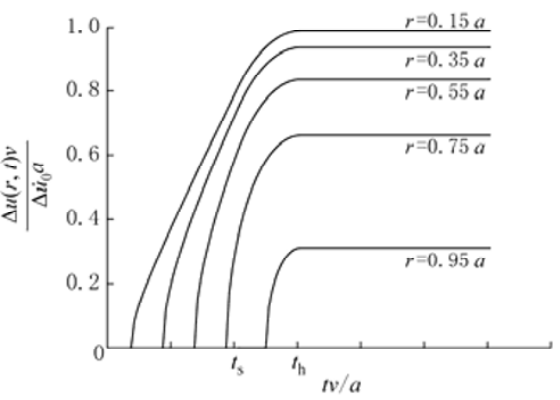

(b)

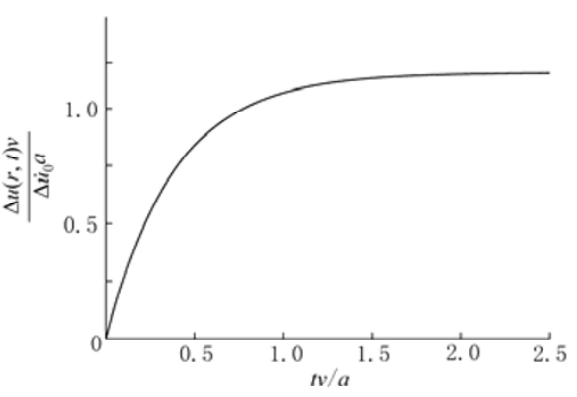

(c)

Figure 2 (a) Slip displacement, $\Delta u$, and slip velocity, $\Delta \dot{u}$, for the M-model with $v_{\mathrm{R}}=0.9 \beta$, at five different radii. The motion at each radius is self-similar until the arrival time of the P-wave stops phase from the perimeter of the fault; (b) Slip displacement, $\Delta u$, and slip velocity, $\Delta \dot{u}$, for the $\mathrm{D}$-model with $v_{\mathrm{R}}=0.9 \beta$, at five different radii. The motion at each radius is self-similar until $\tau_{\mathrm{s}}=0.82 \alpha / v_{\mathrm{R}}$ when the fault begins to decelerate; (c) Brune near-fault slip pulse model in which $\Delta \dot{u}=\Delta \tau_{\mathrm{d}} \beta / \mu \exp \left(-2 \pi f_{c} t\right)$ and corner frequency $f_{\mathrm{c}}=0.37 \beta / \alpha$.

$$
\begin{gathered}
E_{\mathrm{s}}=\frac{\tau_{i}^{0}-\tau_{i}^{1}}{2} \int_{0}^{2 \pi} \int_{0}^{R} \Delta u_{i}^{1} \mathrm{~d} r \mathrm{~d} \theta- \\
\int_{0}^{2 \pi} \int_{0}^{R} \mathrm{~d} r \mathrm{~d} \theta \int_{0}^{\Delta u_{i}^{1}}\left(\tau_{\mathrm{f}}-\tau_{i}^{1}\right) \mathrm{d} \Delta u_{i}-E_{f} .
\end{gathered}
$$

For M- and D-models (Madariaga, 1976, Boatwright, 1980), the radiated energy can be written approximately as

$$
E_{\mathrm{s}}=\frac{\Delta \tau_{\mathrm{d}}^{2}}{\mu} a^{3} \frac{\pi}{3}\left\{\rho_{\mathrm{o}}\left[2-\frac{\Delta \tau_{\mathrm{s}}}{\Delta \tau_{\mathrm{d}}}\right]-g\left(\frac{v_{\mathrm{R}}}{\beta}\right)\right\},
$$

and the exact solution is

$$
E_{\mathrm{s}}=\frac{\Delta \tau_{\mathrm{d}}^{2}}{\mu} a^{3} \frac{\pi}{3}\left\{\rho_{\mathrm{o}}\left[2-\frac{\Delta \tau_{\mathrm{s}}}{\Delta \tau_{\mathrm{d}}}\right] \frac{C\left(\frac{v_{\mathrm{R}}}{\beta}\right)}{\frac{v_{\mathrm{R}}}{\beta}}-g\left(\frac{v_{\mathrm{R}}}{\beta}\right)\right\}
$$

where $\rho_{\mathrm{o}}=1.52$ which is obtained from dynamic solution for a circular model (Madariaga, 1976). $v_{\mathrm{R}}$ is the rupture velocity. $g\left(v_{\mathrm{R}} / \beta\right)$ represents the relative amount of available energy consumed as fracture energy which is given by $E_{\mathrm{f}}=\left(\pi \Delta \tau_{\mathrm{d}} / 3 \mu\right) R^{3} g\left(v_{\mathrm{R}} / \beta\right)$. In M-model, $g\left(v_{\mathrm{R}} / \beta\right)$ varies monotonically from 0.72 at $v_{\mathrm{R}}=0.6 \beta$ to 0.21 at $0.9 \beta$ (Madariaga, 1976). In fact, $g\left(v_{\mathrm{R}} / \beta\right)$ is a complicate function of $v_{\mathrm{R}} / \beta$ and $v_{\mathrm{R}} / \alpha(\beta$ and $\alpha$ are the S- and P-waves velocities, respectively, and its value also strongly depends on the $A_{0}$, the constant slip velocity at the center 
of the fault, which are directly related to the $C\left(v_{\mathrm{R}} / \beta\right.$, $v_{\mathrm{R}} / \alpha$ ), the Kostrov function (Kostrov, 1964, Dahlen, $1974)$ by $C\left(v_{\mathrm{R}} / \beta, v_{\mathrm{R}} / \alpha\right)=A_{0} \alpha / \beta$. As pointed out by Dahlen (1974), the function of $A_{0}$ has a complicate integral expression and is difficult to evaluate in close form. For the special case of a Poisson solid, $\alpha^{2}=3 \beta^{2}$, the numerical solution of $C\left(v_{\mathrm{R}} / \beta\right)$ was given by Dahlen (1974). In the limit $v_{\mathrm{R}} \ll \beta, C\left(v_{\mathrm{R}} / \beta\right) \approx(24 / 7 \pi)\left(v_{\mathrm{R}} / \beta\right)$. Obviously, this limits the application of equation (13) used in the quantitative estimating of radiation energy and source parameter evaluation when the rupture velocity varies during the rupture propagation.

For a circular rupture model, we can obtain the relation of $M_{\mathrm{o}}=16 /\left(7 \Delta \tau_{\mathrm{s}} \alpha^{3}\right)$, where $a$ and $M_{\mathrm{o}}$ can be determined from seismic spectrum. Therefore, the apparent stress for the M- and D-models is

$$
\begin{gathered}
\tau_{\mathrm{a}}=\frac{7 \pi}{48}\left(\frac{\Delta \tau_{\mathrm{d}}}{\Delta \tau_{\mathrm{s}}}\right)^{2} . \\
\left\{\rho_{\mathrm{o}}\left[2-\frac{\Delta \tau_{\mathrm{s}}}{\Delta \tau_{\mathrm{d}}}\right] \frac{C\left(\frac{v_{\mathrm{R}}}{\beta}\right)}{\frac{v_{\mathrm{R}}}{\beta}}-g\left(\frac{v_{\mathrm{R}}}{\beta}\right)\right\} \Delta \tau_{\mathrm{s}} .
\end{gathered}
$$

Table 1 Source parameters vs $v_{\mathrm{R}} / \beta$ from equation (14)

\begin{tabular}{c|ccc}
\hline$V_{r} / \beta$ & 0.6 & 0.75 & $\mathbf{0 . 9}$ \\
\hline$C\left(v_{\mathrm{R}} / \beta\right)$ & 0.59 & 0.71 & 0.82 \\
$g\left(\nu_{\mathrm{R}} / \beta\right)$ & 0.72 & 0.54 & 0.21 \\
$\tau_{d} / \Delta \tau_{\mathrm{s}}\left(\rho_{\mathrm{o}}=1\right)$ & 0.20 & 0.32 & 0.56 \\
$\tau_{d} \Delta \tau_{\mathrm{s}}\left(\rho_{\mathrm{o}}=1.52\right)$ & 0.05 & 0.12 & 0.23 \\
\hline
\end{tabular}

It is obvious that, with a given $\Delta \tau_{s}$, the apparent stress from the D-model is much larger than the apparent stress of the M-model, and D-model exhibits a frictional undershoot because of $\Delta \tau_{\mathrm{s}} / \Delta \tau_{\mathrm{d}}<1$ resultant from equation (2).

\section{Near-fault work}

When a crack with radius $a$ is inserted into a homogeneous medium under a uniform shear stress, the strain energy is released. After subtracting the energy dissipated in friction, the strain energy change is given by $\Delta W_{\mathrm{o}}=\pi a^{2} \Delta \tau_{\mathrm{s}} \bar{D} / 2$, which is available for mechanical work for crack extension. During fault slip motion, a dynamic frictional overshoot or undershoot can occur. Indeed, the M- and D-models exhibit frictional overshoot and undershoot, respectively. For a frictional overshoot mechanism, $\tau_{i}^{1}$, the final stress is larger than $\tau_{\mathrm{f}}$, the frictional stress, and $\quad W_{\mathrm{r}}=\left(\tau_{\mathrm{f}}-\tau_{1}\right) \bar{D} \pi a^{2}=\pi a^{2} \bar{D}\left(\Delta \tau_{\mathrm{d}} / \Delta \tau_{\mathrm{s}}-1\right)$ $\Delta \tau_{\mathrm{s}}$ is the work done by the stress relaxation on the fault after the arrest of the slip as discussed by Favreau and Archeluta (2003). Therefore, the work done during the coseismic deformation should be

$$
\begin{gathered}
W^{\prime}=\Delta W_{\mathrm{o}}-W_{\mathrm{r}}=\frac{\pi a^{2} \bar{D}}{2}\left[2 \frac{\Delta \tau_{\mathrm{d}}}{\Delta \tau_{\mathrm{s}}}-1\right] \Delta \tau_{\mathrm{s}}= \\
\frac{M_{\mathrm{o}}}{2 \mu}\left[2 \frac{\Delta \tau_{\mathrm{d}}}{\Delta \tau_{\mathrm{s}}}-1\right] \Delta \tau_{\mathrm{s}} .
\end{gathered}
$$

Thus, the near-fault energy can be calculated by

$$
\begin{gathered}
E_{\mathrm{nf}}=E_{\mathrm{s}}+W^{\prime}=\frac{7 \pi}{48} \frac{M_{\mathrm{o}}}{\mu}\left(\frac{\Delta \tau_{\mathrm{d}}}{\Delta \tau_{\mathrm{s}}}\right)^{2}\left\{\rho_{\mathrm{o}}\left[2-\frac{\Delta \tau_{\mathrm{s}}}{\Delta \tau_{\mathrm{d}}}\right] .\right. \\
\left.\frac{C\left(\frac{v_{\mathrm{R}}}{\beta}\right)}{\frac{v_{\mathrm{R}}}{\beta}}-g\left(\frac{v_{\mathrm{R}}}{\beta}\right)\right\} \Delta \tau_{\mathrm{s}}+\frac{M_{\mathrm{o}}}{2 \mu}\left[2 \frac{\Delta \tau_{\mathrm{d}}}{\Delta \tau_{\mathrm{s}}}-1\right] \Delta \tau_{\mathrm{s}} .
\end{gathered}
$$

The ratio of far-field energy to near-fault energy is

$$
f\left(v_{\mathrm{R}}\right)=\frac{E_{\mathrm{s}}}{E_{\mathrm{nf}}}=\frac{\tau_{\mathrm{a}}}{\tau_{\mathrm{a}}+\frac{1}{2} \Delta \tau_{\mathrm{s}}\left(2 \frac{\Delta \tau_{\mathrm{d}}}{\Delta \tau_{\mathrm{s}}}-1\right)}=\frac{\tau_{\mathrm{a}}}{\tau_{\mathrm{a}}+\frac{C^{\prime}}{2} \Delta \tau_{\mathrm{s}}} .
$$

$C^{\prime}=2 \Delta \tau_{\mathrm{d}} / \Delta \tau_{\mathrm{s}}-1 \geq 0$. In fact, equations (16) and (17) is also satisfied for the D-model case. A $C^{\prime}>1$ implies a partial stress drop mechanism or frictional undershoot whereas $C^{\prime}<1$ indicates that frictional overshoot has occurred. Orowan's hypothesis is met when $C^{\prime}=1$. In the overshoot case, the minimum bound of $C^{\prime}=0$ provides a way to check for inconsistencies in source parameters. If $v_{\mathrm{R}} / \beta=0.9$, then $C\left(v_{\mathrm{R}} / \beta=0.9\right)=0.82$. In this case, we have $\Delta \tau_{\mathrm{s}}=\Delta \tau_{\mathrm{d}}=1.2$ for the M-model and $\Delta \tau_{\mathrm{s}}=\Delta \tau_{\mathrm{d}}=0.8$ for the D-model. Therefore, in these three cases, the ratio of $E_{\mathrm{s}}$ to $E_{\mathrm{nf}}$ are

$$
f\left(v_{\mathrm{R}}\right)=\frac{E_{\mathrm{s}}}{E_{\mathrm{nf}}}==\left\{\begin{array}{ll}
\frac{\tau_{\mathrm{a}}}{\tau_{\mathrm{a}}+0.3 \Delta \tau_{\mathrm{s}}} & \text { overshoot } \\
\frac{\tau_{\mathrm{a}}}{\tau_{\mathrm{a}}+0.7 \Delta \tau_{\mathrm{s}}} & \text { undershoot } \\
\frac{\tau_{\mathrm{a}}}{\tau_{\mathrm{a}}+0.5 \Delta \tau_{\mathrm{s}}} & \text { total stress drop }
\end{array} .\right.
$$

Based on the M-model, McGarr and Fletcher (2001) first gave the similar result to equation (18) without consideration of frictional overshoot and undershoot inherited in the M- or D-models. It need to point out that, 
in fact, M-model itself is a frictional overshoot model because $\Delta \tau_{\mathrm{d}} / \Delta \tau_{\mathrm{s}}$ is always less than 1 . Thus, the equation we have derived is a generalized form involved different frictional mechanisms and has a clear physical meaning that, when $E_{\mathrm{s}}$ or $\tau_{\mathrm{a}}$ equal to $0, E_{\mathrm{nf}}$ also equal to 0 , because, in such case, $\Delta \tau_{\mathrm{s}} / \Delta \tau_{\mathrm{d}}=2$ corresponds to $C^{\prime}=0$.

\subsection{Near-fault slip motion}

Based on the time history of slip across a fault, the near-field seismic energy $E_{\mathrm{nf}}$ can also be calculated using (Anooshehpoor and Brune, 1994)

$$
E_{\mathrm{nf}}=\int \mathrm{d} A \rho \beta \int \frac{\dot{D}^{2}(t) \mathrm{d} t}{2}=\int \frac{\mathrm{d} A \rho \beta \bar{D}<\dot{D}>}{2},
$$

where the integrations are over fault area $A$ and time $t, \rho$ is density, $D(t)$ is the time-dependent slip or approximately as the near-fault ground velocity. The slip weigh ted average slip velocity can be defined as

$$
<\dot{D}>=\int \frac{\dot{D}(t) \mathrm{d} D}{\bar{D}}=\frac{\int \dot{D}(t) \frac{\mathrm{d} D}{\mathrm{~d} t} \mathrm{~d} t}{\bar{D}}=\frac{\int \dot{D}^{2}(t) \mathrm{d} t}{\bar{D}}
$$

where $\bar{D}$ is the final slip (average). From equations (16) and (17), we have

$$
<\dot{D}>=2 \frac{\tau_{\mathrm{a}}+\left(\frac{2 \Delta \tau_{\mathrm{d}}}{\Delta \tau_{\mathrm{s}}}-1\right) \frac{\Delta \tau_{\mathrm{s}}}{2}}{\mu} \beta
$$

For a total stress drop model, $\Delta \tau_{\mathrm{d}} / \Delta \tau_{\mathrm{s}}=1$, $<\dot{D}>=\left(2 \tau_{\mathrm{a}}+\Delta \tau_{\mathrm{s}}\right) \beta / \mu$, otherwise, equation (20) can be written as

$$
<\dot{D}>=2\left\{\tau_{\mathrm{a}}+\left(\frac{48}{7 \pi} \frac{\frac{v_{\mathrm{R}}}{\beta}}{C\left(\frac{v_{\mathrm{R}}}{\beta}\right)} \frac{1}{\rho_{\mathrm{o}}}-1\right) \frac{\Delta \tau_{\mathrm{s}}}{2}\right\} \frac{\beta}{\mu}
$$

In fact, equations (20) and (21) can be used to constrain the slip velocity on the fault or near-field ground motion such as weighted average particle velocity approximately if we know far-field radiated energy, seismic moment and rupture speed. In the other hand, if we have near-field strong ground motion recordings and know the static stress drop, the average rupture speed also can be estimated from equation (21). What we need to know in these calculations is the dynamic frictional mechanisms during the earthquake faulting. Because parameter $\rho_{\mathrm{o}}$ are model-dependent constants, the frictional overshoot or undershoot mechanisms can directly described by the M- and D-models, respectively. Accordingly, with the definition given by Savage and Wood (1971), the parameter, denoted by $\varepsilon=\Delta \tau_{\mathrm{s}} /\left(\tau_{\mathrm{a}}+\right.$ $0.5 \Delta \tau_{\mathrm{s}}$ ) (Ramon-Zuniga, 1993) could be used to classify the frictional models if the apparent stress $\tau_{\mathrm{a}}$ and static stress drop $\Delta \tau_{\mathrm{s}}$ is known. $\varepsilon$ is greater than 1 for a frictional overshoot mechanism and $\varepsilon$ is less 1 for a frictional undershoot mechanism (Kanamori, 2006) or a partial stress drop model (Brune, 1970). For most large shallow earthquakes, it is generally established that the rupture speed is about $75 \%$ to $85 \%$ of $\beta$ (Kanamori and Heaton, 2000). Kanamori and Heaton (2000) also indicated that a reasonable range of $\Delta \tau_{\mathrm{s}}$ is about $3 \mathrm{MPa}$ to 10 $\mathrm{MPa}$, and $\Delta \tau_{\mathrm{d}}$ varies from $3 \mathrm{MPa}$ to $11 \mathrm{MPa}$ correspondingly. Abercrombie and Rice (2005) suggested that the ratio of $\Delta \tau_{\mathrm{s}} / \tau_{\mathrm{a}}$ of about 10 should be reasonable for large earthquake if the far-field radiated energy measurements are correct. If this conclusion is right, then $\varepsilon \approx 1.67 \mathrm{im}$ plies that the large earthquakes undertake a strong frictional overshoot mechanism. If an average $\tau_{\mathrm{a}}$ is about 0.7 $\mathrm{MPa}$ (Perez-Campos et al, 2003), the ratio of $\Delta \tau_{\mathrm{s}} / \tau_{\mathrm{a}}=10$ implies an average stress drop for large earthquakes of 7 $\mathrm{MPa}$, and if the ratio is 3, then it would imply an average stress drop of 2.1 $\mathrm{MPa}$. Based on the M-model, the ratio of $\Delta \tau_{\mathrm{s}} / \tau_{\mathrm{a}}$ is about 10 also implies an average rupture speed is about $75 \%$ of shear wave speed. Therefore, the weighted average particle velocity from equation (21) is about $56 \mathrm{~cm} / \mathrm{s}$ if $\mu=3.0 \times 10^{5} \mathrm{MPa}$ is used for the rigidity of the crust and shear wave speed $\beta=3 \mathrm{~km} / \mathrm{s}$ is used in our calculation. The Brune model of $\dot{u}=\Delta \sigma \beta / \mu$ predicts the peak ground velocity (PGV) is about $70 \mathrm{~cm} / \mathrm{s}$, and the PGV predicted by McGarr and Fletcher (2001) approach is about $84 \mathrm{~cm} / \mathrm{s}$. Actually, the Brune model is an instantaneous model without any consideration of finite rupture speed during earthquake faulting. In the other hand, McGarr and Fletcher's approach is a specific case, corresponding to $\Delta \tau_{\mathrm{s}} / \Delta \tau_{\mathrm{d}}=1$ in equation (20). Although they have used the M-model solution in their derivation of near-fault seismic energy equation, the resultant function given by equation (2) ignores the apparent differentials existing in the calculation of near-fault work with or without considering of different frictional mechanisms. It is obvious that both Brune model and McGarr and Fletcher's approach usually overestimate the near-fault ground motion or the slip rate on the fault. 


\subsection{Applications}

Case 1: May 12, $2008 M_{\mathrm{W}} 7.9$ great Wenchuan earthquake

The 2008 Wenchuan, Sichuan, China, earthquake $\left(M_{\mathrm{W}} 7.9\right)$ characterized by dip-slip reverse faulting, ruptured about $300 \mathrm{~km}$ along a northeast-striking, west-dipping Longmenshan thrust fault belt located on the margin of the eastern Tibetan plateau. Based on the earthquake catalogs from GCMT, USGS/NEIC, and Chinese Earthquake Network Center (CENC), including USGS energy and broadband solution, the primary source parameters given that, for Wenchuan event, the seismic moment $M_{\mathrm{o}}=7.6 \times 10^{20} \mathrm{~N} \cdot \mathrm{m}$ and the far-field radiated energy $E_{\mathrm{s}}=1.4 \times 10^{16} \mathrm{~N} \cdot \mathrm{m}$, and the corresponding apparent stress, $\tau_{\mathrm{a}}$, is about $0.55 \mathrm{MPa}$ if $\mu=3.0 \times 10^{5} \mathrm{MPa}$ is used in our calculation. The static stress drop derived from in-situ borehole strain meter data recorded at the Central Longmenshan fault zone is about 2.6 MPa which is consistent with the result of $2.58 \mathrm{MPa}$ estimated by $\Delta \tau_{\mathrm{s}}=C_{\mathrm{s}} D / W$ for a long dip-slip earthquake, where $D \sim 2.3 \mathrm{~m}$ (Wang et al, 2008) is the average slip and $W \sim 22$ $\mathrm{km}$ is the average width, and $C_{\mathrm{s}}$ is the geometrical factor given by $\left.C_{\mathrm{s}}=4(\lambda+\mu) /[\pi(\lambda+2 \mu))\right]$ or $C_{s}=8(\lambda+\mu) /[\pi(\lambda+2 \mu)]$ depending on whether the slip breaks the free surface or not. Moreover, according to the Savage and Wood (1971) inequality, $\tau_{\mathrm{a}}<<\Delta \tau_{\mathrm{s}}$ also indicates that, for the 2008 Wenchuan earthquake, the dynamic frictional motion on the fault underwent an overshoot process. Strong motion records from the main shock shows that The National Strong Motion Observation Network System (NSMONS) reported that more than 460 strong motion stations were triggered and the largest peak ground acceleration was recorded at Wolong station in Wenchuan county which is located on the hanging wall and about $14 \mathrm{~km}$ close to main fault. The PGAs recorded in the EW, NS, and UD directions are $957.7 \mathrm{~cm} / \mathrm{s}^{2}, 652.9 \mathrm{~cm} / \mathrm{s}^{2}$ and $948.1 \mathrm{~cm} / \mathrm{s}^{2}$, respectively. The strong ground motion records obtained at Qingping station in Mianzhu city ranks the second largest one in PGA. It's PGAs recorded in the EW, NS and UD directions are $824.1 \mathrm{~cm} / \mathrm{s}^{2}, 802.7 \mathrm{~cm} / \mathrm{s}^{2}$ and 622.9 $\mathrm{cm} / \mathrm{s}^{2}$, respectively. The station location is near the middle of rupturing fault which is indicated in Figure 3, and the nearest distance to the main fault is about $5 \mathrm{~km}$. Inside Figure 3, the waveforms of ground velocity time histories recorded at Qingping station and simulated by composite source model for Qingping station are also displayed. With the integration of $\int_{0}^{t} \vec{V} \cdot \vec{V} \mathrm{~d} t$ divided by

$\bar{D}$, the average slip displacement, Figure 4 shows the cumulative values of weighted average particle velocities in time domain at Qingping station. For a comparison purpose, the simulated results are also shown in this figure. It is clear that the resultant $\langle\dot{D}\rangle_{I}$ is about $27 \mathrm{~cm} / \mathrm{s}$ for real recordings and about $30 \mathrm{~cm} / \mathrm{s}$ for strong motion simulation. Based on the source parameters

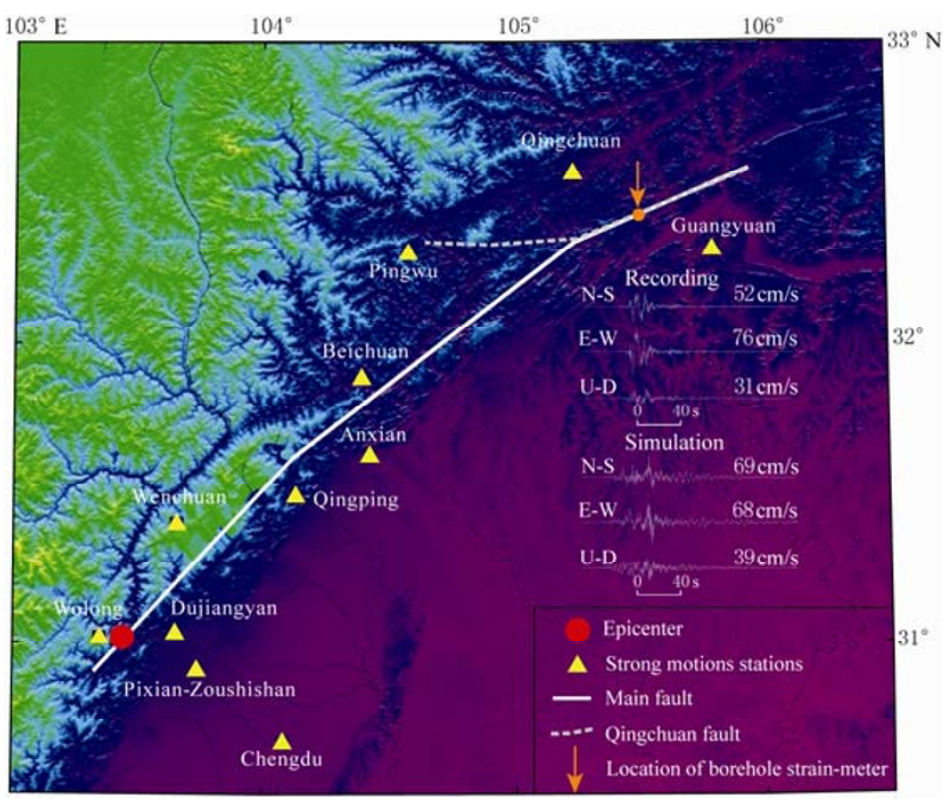

Figure 3 The spatial distribution of the main fault along the Longmenshan fault zone for the 2008 $M_{\mathrm{W}} 7.9$ great Wenchuan earthquake. The nearest station is located in Qingping with a shortest distance to the main fault of about $5 \mathrm{~km}$. The strong recordings and simulated waveforms also are displayed inside this figure. 


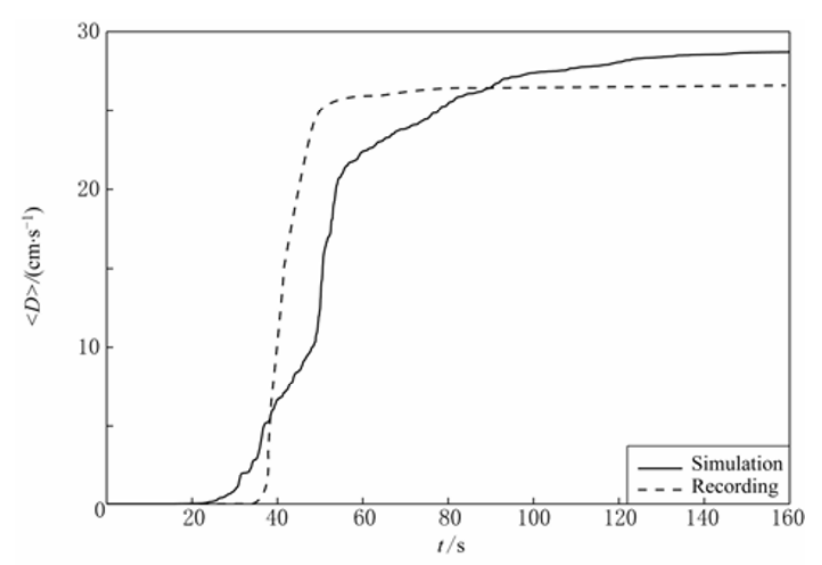

Figure 4 Cumulative squared velocity for Qingping recordings and numerical simulation.

Table 2 Slip weighted average velocities derived from equation (21) for different values of $v_{\mathrm{R}} / \beta$

\begin{tabular}{cccc}
\hline$\nu_{\mathrm{R}} / \boldsymbol{\beta}$ & $\mathbf{0 . 9}$ & $\mathbf{0 . 7 5}$ & $\mathbf{0 . 6}$ \\
\hline$\left\langle\dot{D}>_{D} / \mathrm{cm} \cdot \mathrm{s}^{-1}\right.$ & 26 & 24.4 & 23.0 \\
\hline
\end{tabular}

shown in Figure 3, we also derived the weighted average particle velocity of $\langle\dot{D}>$ from equation (21) with $v_{\mathrm{R}} / \beta$ ranging from 0.6 to 0.9 (Table 2). Obviously, these results listed in Table 2 are much similar to that obtained by integration of squared velocity time histories of Qingping recording, but much smaller than $37 \mathrm{~cm} / \mathrm{s}$ obtained by McGarr and Fletcher approach given by $\left\langle\dot{D}>=2\left(\tau_{\mathrm{a}}+0.5 \Delta \tau_{\mathrm{s}}\right)\right.$ In other words, if we havenear-fault strong motion recordings and know far-field radiated seismic energy, equations (20) and (21) can also be used to estimate the dynamic stress drop and static stress drop based on the M-model, D-model or Brune model. The only thing we need to take care is that, when we use Brune model for estimating, the resultant stress drop is only $1 / 5$ times of M-model or the size of localized subevent is about 1.7 times of M-model.

Case 2: September 21, $1999 M_{\mathrm{W}} 7.6 \mathrm{Jiji}$ earthquake

The 1999 Jiji earthquake $\left(M_{\mathrm{W}} 7.6\right)$ ruptured the ground surface along the Chelunpu fault in central Taiwan of China. The earthquake triggered almost all strong motion stations operated by the Central Weather Bureau around the epicentral area. Results from near-fault ground motion observations as well as from far-field seismograms revealed that the fault of the Jiji earthquake can be divided into two segments that break the surface and the character of ground motions exhibits a major change between the southern and northern segments of the fault in which there are two significant moment releases during the faulting. Both segments of the fault exhibit thrust type of motions, the average dislocation in southern part is about $1 \mathrm{~m}$, in contrast, the average dislocation in northern part reaches about $6 \mathrm{~m}$ (Xu et al, 2002) or $8 \mathrm{~m}$ (Huang et al, 2001). In this study, we use strong motion recordings from three nearest stations to the main fault to infer the weighted average particle velocities close to the fault and make a

comparison with the result derived from equation (21). The strong recordings we have used are TCU052, TCU102 and TCU076. The locations of stations are shown in Figure 5a. TCU076 is on the footwall and near the southern segments with a shortest distance to the main fault about $3.2 \mathrm{~km}$. TCU052 and TCU102 are near the northern segment and far from the epicenter. The shortest distances to the main fault for TCU052 and TCU102 are $1.8 \mathrm{~km}$ and $1.2 \mathrm{~km}$, respectively. The station of TCU052 is located on the hanging wall and the stations of TCU102 and TCU076 are on the footwall. From the U.S. Geological Survey earthquake catalog, $M_{\mathrm{o}}=2.4 \times 10^{20} \mathrm{~N} \cdot \mathrm{m}$, and the value of $E_{\mathrm{s}}$ estimated from the method developed by Choy and Boatwright (1995) is $1.2 \times 10^{16} \mathrm{~N} \cdot \mathrm{m}$. This leads to $E_{\mathrm{s}} / M_{\mathrm{o}}=5.0 \times 10^{-5}$ or the apparent stress $\tau_{\mathrm{a}}$ is about $1.5 \mathrm{MPa}$. Figure $5 \mathrm{~b}$ shows the time histories of velocities recorded at stations of TCU052, TCU102 and TCU076. Figure 6 shows the cumulative values of weighted average particle velocities of $\langle\dot{D}\rangle_{\mathrm{I}}$ in time domain at TCU052, TCU102 and TCU076. The source parameters used in $\langle\dot{D}\rangle_{\mathrm{D}}$ estimating from equation (21) are given in Table 3 , and the final results of $\langle\dot{D}\rangle_{\mathrm{D}}$ which obtained both from equation (21) and the integration of squared particle velocity time histories are also summarized in Table 3. The subscripts of I and $\mathrm{D}$ indicate, $<\dot{D}>$, the weighted average velocities are obtained both from direct integration of squared particle velocity recordings and deriving by equation (21), respectively.

$\underline{\text { Table } 3 \text { Source parameters and derived average particle velocity }}$

\begin{tabular}{lrrrcc}
\hline \multirow{2}{*}{ Station } & $\Delta \tau_{\mathrm{s}} / \mathrm{MPa}$ & $\left\langle\dot{D}>_{\mathrm{I}} / \mathrm{cm} \cdot \mathrm{s}^{-1}\right.$ & \multicolumn{3}{c}{$\left\langle\dot{D}>_{\mathrm{D}} / \mathrm{cm} \cdot \mathrm{s}^{-1}\right.$} \\
\cline { 4 - 6 } & & & $v_{\mathrm{R}} / \beta=0.9$ & $v_{\mathrm{R}} / \beta=0.75$ & $v_{\mathrm{R}} / \beta=0.6$ \\
\hline TCU102 & 19 & 24 & 41 & 40 & 38.7 \\
TCU052 & 202 & 138 & 147 & 134 & 123 \\
TCU076 & 54 & 59 & 61 & 58 & 55 \\
\hline
\end{tabular}

\section{Discussion and conclusions}

The results of this study show that there are still certain uncertainities in our understanding of earthquake 


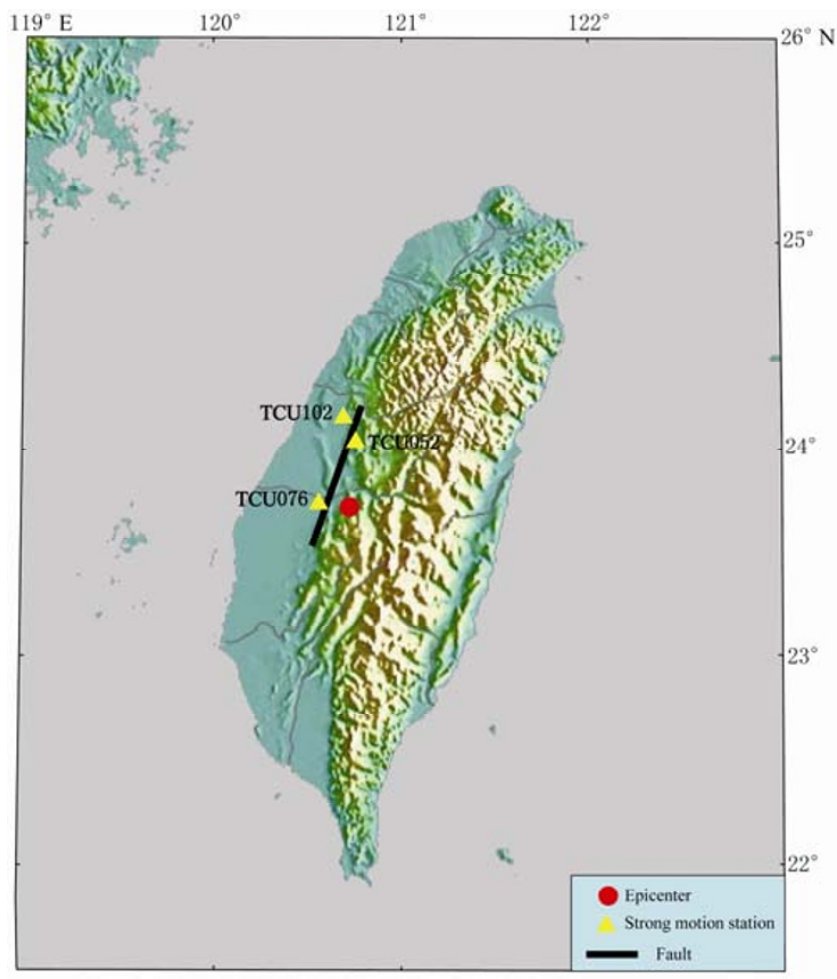

(a)
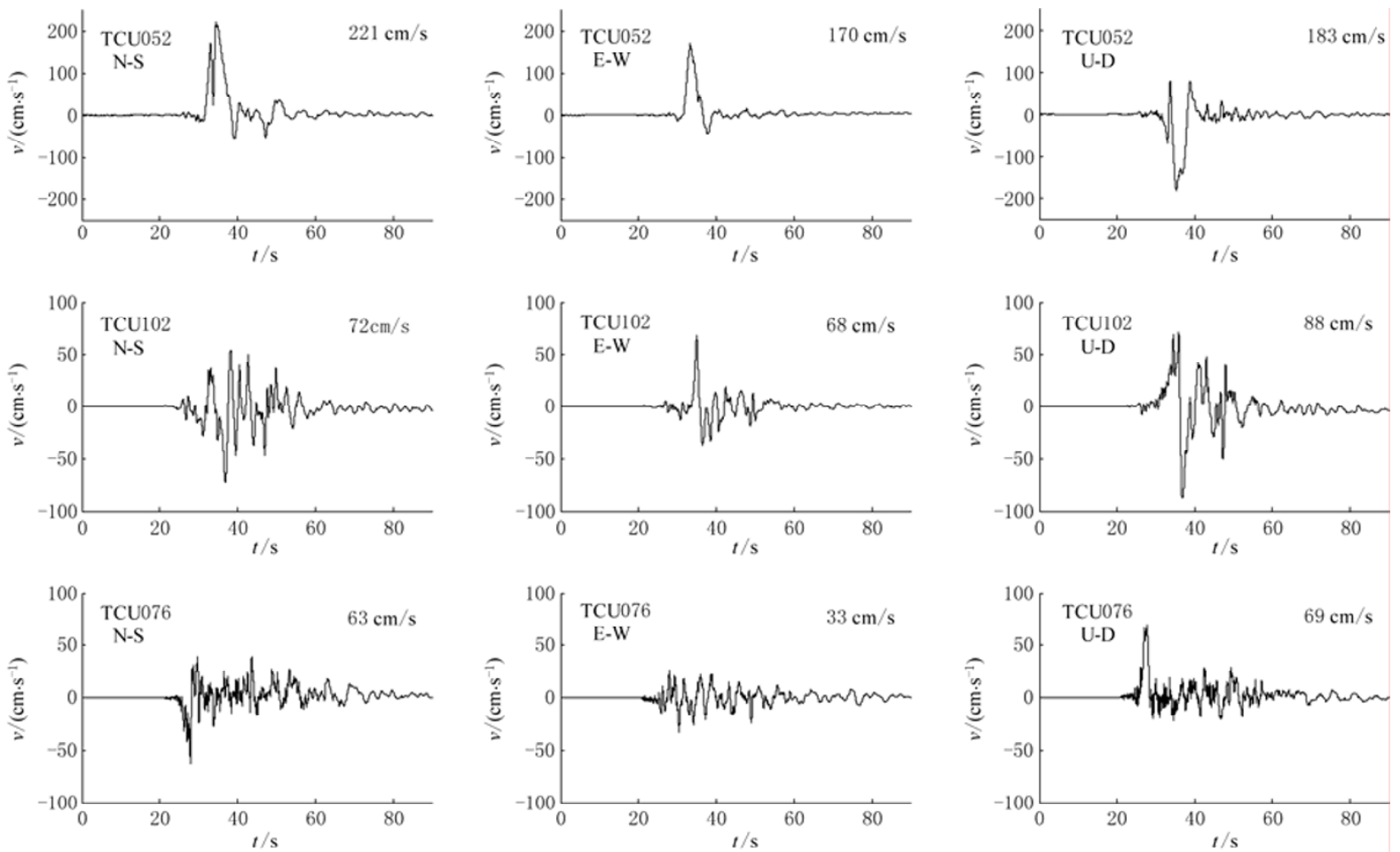

(b)

Figure 5 The main fault and locations of strong motions for the $1999 M_{\mathrm{W}} 7.6 \mathrm{Jiji}$ earthquake (a); Three components of the particle velocity time histories at three stations (b). 


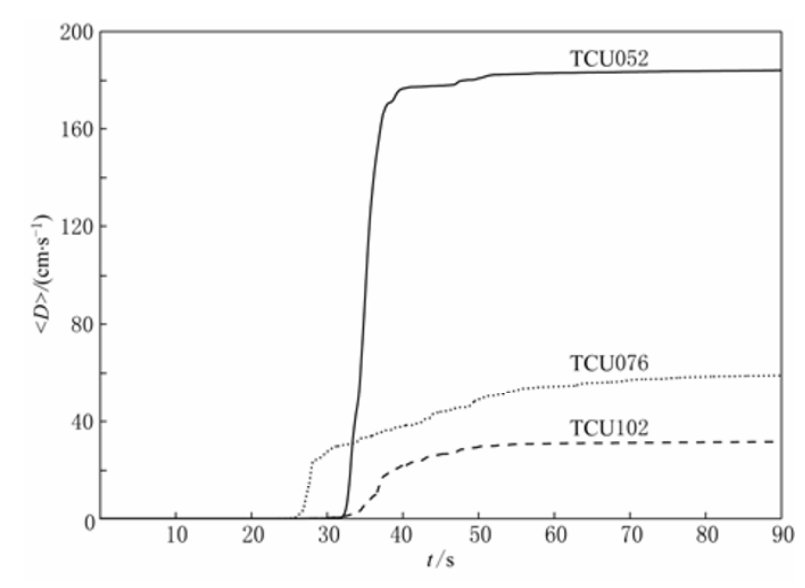

Figure 6 Cumulative squared velocity for TCU052, TCU102 and TCU076 recordings.

faulting process. The results do enable us to place some constraints on the near-fault ground motion prediction,but the accuracy of measurements of radiated seismic energy, rupture speed and stress drop is still our future concern. The mechanisms of the dynamic frictional overshoot or undershoot during the earthquake faulting are also arguable, and as new high quality data are gathered and improvements are made on current evaluation techniques, it will be possible to better quantify parameters such as the ratio of $\Delta \tau_{\mathrm{s}} / \Delta \tau_{\mathrm{d}}$, which will provide a better description of the source process. Brune model and M-model (Madariaga, 1976) are in conmmon usage for determining earthquake source paramters from the spectra measurements of $\Omega_{\mathrm{o}}$ and corner frequency $f_{\mathrm{c}}$. For $v_{\mathrm{R}}=0.9 \beta$, the $\mathrm{M}$-model is identical to Brune model with $\tau_{\mathrm{a}}=0.23 \Delta \tau_{\mathrm{s}}$. The principal difference between these two models in their usage is that the rupture radius derived from the S-wave spectra using Brune model is 1.77 times that obtained using M-model. Therefore, the stress drop obtained using M-model is 5.5 times those from the Brune model. Both the Brune and M-model are in current use for interpreting seismic with no consensus as to which gives the most accurate results. For a diping fault, asymmetric near-fault ground motion caused by the asymmetric geometry of thrust fault is not included in this study. Dynamic simulation of thrust faulting (Oglesby et al, 1998, Shi et al, 1998) indicates the motion of the hanging wall is larger than that of the footwall. The ratio of the near-fault peak ground velocities between the hanging wall and footwall is about $3-4$ for a $30^{\circ}$ dipping thrust fault. For example, if we take into account such geometric effect related to the larger amplification of ground motion on the hanging wall described by waveform at station TCU052 recordings, the resultant stress drop is about $2.0 \mathrm{MPa}$ by using equation (21), which is similar to $1.9 \mathrm{MPa}$ estimated from the waveforms at station TCU102 (Hwang et al, 2001), and the inconsistances of stress drops ranging from 1.9 MPa from TCU102 to 20.2 MPa from TCU052 for the same segment of the main fault can be removed.

Following McGarr and Fletcher (2001) approach with a combination of far-field radiated seismic energy, seismic moment and near-fault deformation work, in this study we derived the relationship of fault slip velocity vs apparent stress, rupture speed and static stress drop. Comparing with previous derivation given by McGarr and Fletcher, the current result includes the consideration of the dynamic frictional overshoot and undershoot mechanisms described by M- and D-models (Boatwright, 1980, Madariaga, 1976). We applied this technique to the 2008 great Wenchuan earthquake and the 1999 Jiji (Chi-Chi) earthquake, and obtained the weighted average particle velocities for each event. Moreover, we compared the model-dependent predictions of $\langle\dot{D}\rangle$ to the results obtained by direct integration of squared particle velocity waveforms observed at near-fault strong motion stations, and we found that the values we obtained for $\langle\dot{D}\rangle$ are in the same range of numerical integration of real seismic data. If this result comes to be true, it would be a straightforward way of obtaining the source parameters, such as static and dynamic stress drop, rupture speed or average slip on the fault, if we have the near-fault strong motion data and make the measurement of the seismic moment and far-field seismic energy correctly.

Acknowledgments This work was supported by the Knowledge Innovation Program of Chinese Academy of Sciences (KZCX2-YW-Q08-2) and One-Hundred-Individual Program of Chinese Academy of Sciences.

\section{References}

Abercrombie R E and Rice J R (2005). Can observations of earthquake scaling constrain slip weakening? Geophys J Int 162(2): 406-424.

Anooshehpoor A and Brune J N (1994). Frictional heat generation and seismic radiation in a foam rubber model of earthquakes. Pure Appl Geophys 142(3-4): 735-747.

Boatwright J L (1980). Spectral theory for circular seismic sources: Simple estimates of source dimension, dynamic stress drop, and radiated seismic energy. Bull Seism Soc Amer 70(1): 1-27.

Brune J N (970). Tectonic stress and the spectra of seismic shear waves from earthquakes. $J$ Geophys Res 75(26): 4 997-5 009. 
Brune J N and Thatcher W (2002). Strength and energetic of active fault zones. In: Lee W, Kanamori $\mathrm{H}$, Jennings $\mathrm{P}$ and Kisslinger $\mathrm{C}$ eds. International Handbook of Earthquake and Engineering Seismology. Part A. Academic Press, California, USA, 569-588.

Choy G L and Boatwright J L (1995). Global patterns of radiated seismic energy and apparent stress. J Geophys Res 100(B9): 18 205-18 228.

Choy G L and Boatwright J L (2009). Differential energy radiation from two earthquakes in Japan with identical $M_{\mathrm{W}}$ : The Kyushu 1996 and Tottori 2000 earthquakes. Bull Seism Soc Amer 99(5): 1 815-1 826.

Choy G L, McGarr A, Kirby S H and Boatwright J L (2006). An overview of the global variability in radiated energy and apparent stress. In: Abercrombie R, McGarr A, Kanamori H and Di Toro G eds. Geophysical Monograph: 170. American Geophysical Union, Washington D C, 43-57.

Cocco M, Spudich P and Tinti E (2006). On the mechanical work absorbed on faults during earthquake ruptures. In: Abercrombie R, McGarr A, Di Toro G, In: Abercrombie R, McGarr A, Kanamori H and Di Toro G eds. Geophysical Monograph. 170. American Geophysical Union, Washington D C 237-254.

Dahlen F A (1974). On the ratio of P-wave to S-wave corner frequencies for shallow earthquake source. Bull Seism Soc Amer 64(4): 1 159-1 180.

Favreau P and Archuleta R J (2003). Direct seismic energy modeling and application to the 1979 Imperial Valley earthquake. Geophys Res Lett 30(5): doi: $10.1029 / 2002$ GL015968.

Huang W, Wang J, Huang B, Chen K, Chang T, Hwang R, Chiu H and Tsai (2001). Estimates of source parameters for the 1999, Chi-Chi, Taiwan, Earthquake based on Brune's source model. Bull Seism. Soc Amer 91(5): 1 190-1 198.

Hwang R, Wang J, Huang B, Chen K, Huang W, Chang T, Chiu H and Tsai P (2001). Estimates of stress drop of the Chi-Chi, Taiwan, earthquake of 20 September 1999 from near-field seismograms. Bull Seism Soc Amer 91(5): $1158-1166$.

Kanamori H and Heaton T H (2000). Microscopic and macroscopic mechanisms of earthquakes. In: Rundle J, Turcotte D L and Klein W eds. American Geophysical Monograph: GeoComplexity and Physics of Earthquakes 120: 147-163.
Kanamori H and Rivera L (2006). Energy partitioning during an earthquake. In: Abercrombie R, McGarr A, Kanamori H and Di Toro D eds. Geophysical Monograph: 170. American Geophysical Union, Washington D C, 3-13.

Kostrov B V (1964). Self-similar problems of propagation of shear cracks. $J$ Appl Math Mech 28: $1077-1087$.

Madariaga R (1976). Dynamics of an expanding circular fault. Bull Seism Soc Amer 66(3): 639-666.

McGarr A and Fletcher J B (2001). A method for mapping apparent stress and energy radiation applied to the 1994 Northridge earthquake fault zone-revised. Geophys Res Lett 28(18): 3 529-3 532.

McGarr A and Fletcher J B (2002). Mapping apparent stress and energy radiation over fault zones of major earthquakes. Bull Seism Soc Amer 92(5): $1633-1646$.

Oglesby D D, Archuleta R J and Nielsen S B (1998). Earthquakes on dipping faults: The effects of broken symmetry. Science 280(5366): 1 055-1 059.

Perez-Campos X and Beroza G C (2001). An apparent mechanism dependence of radiated seismic energy. J Geophys Res 106(B6): 11 127-11 136.

Ramon-Zuniga F (1993). Frictional overshoot and partial stress drop: Which one? Bull Seism Soc Amer 83(3): 939-944.

Rivera L and Kanamori H (2005). Representations of the radiated energy in earthquakes. Geophys J Int 162(1): 148-155.

Savage J C and Wood M D (1971). The relation between apparent stress and stress drops. Bull Seism Soc Amer 61(5): 1381-1 388.

Shi B, Anooshehpoor A, Brune J N and Zeng Y (1998). Dynamics of thrust faulting: 2D lattice model. Bull Seism Soc Amer 88(6): 1484-1 494.

Wang W M, Zhao L F, Li J and Yao Z X (2008). Rupture process of the $M_{\mathrm{S}} 8.0$ Wenchuan earthquake of Sichuan, China. Chinese $J$ Geophys 51(5): 1403-1 410 (in Chinese).

Wyss M and Brune J N (1968). Seismic moment, stress, and source dimensions for earthquakes in California-Nevada region. $J$ Geophys Res 73(14): 4681- 4694.

Xu L S, Chen Y T, Teng T L and Patau G (2002). Tempo-spatial rupture process of the 1999, $M_{\mathrm{S}} 7.6$, Chi-Chi, earthquake from IRIS and GEOSCOPE long period waveform data using aftershocks as empirical Green's functions. Bull Seism Soc Amer 92(8): 3210-3 228. 